\title{
Snackomat - A Vending Machine To Create Positive Experiences By Bringing People In Contact And Initiating Small Talk In Waiting Situations
}

\author{
Michael Burmester ${ }^{1} \cdot$ Magdalena Laib $^{1} \cdot$ Ralph Tille $^{1}$
}

Accepted: 31 March 2020 / Published online: 30 May 2020

(C) The Author(s) 2020

\begin{abstract}
The "Snackomat" is a vending machine offering snacks for free, installed in waiting situations, and is designed to initiate small talk and therewith to create a positive experience. Here, we experimentally compare the effect on user experience of the Snackomat to the effect of a coffee machine as control condition with 58 participants. Participants' behaviour was observed in waiting situations where observers were blind to the study's objective. The two experimental conditions were compared with an analysis of covariance. The alpha levels were Bonferroni corrected. Significant results with strong effect size indicate that the Snackomat was more effective in creating positive experiences than a coffee machine in a control condition. However, the experimental setting most likely attenuated differences between the two conditions. Future studies should thus replicate the findings in a natural setting. Nevertheless the Snackomat is a promising application example of designing for positive experiences.
\end{abstract}

Keywords User studies · Laboratory experiments · Positive design · User experience · Small talk

Magdalena Laib

laib@hdm-stuttgart.de

Michael Burmester

burmester@hdm-stuttgart.de

Ralph Tille

tille@hdm-stuttgart.de

1 Information Experience and Design Research Group, Stuttgart Media University, Nobelstraße 10, 70569 Stuttgart, Germany 


\section{Theory}

\subsection{Introduction}

Imagine the following situation: You are sitting at the gate of the airport waiting for boarding, but no activity can be seen at the gate desk. Suddenly the person next to you is asking you for the time and a conversation develops. You talk about interesting topics, occasionally your counterpart makes you laugh out loud. You do not realize how fast time has passed until it is time for boarding. At home you tell your partner what a nice conversation you had.

Two weeks later you are at the post office to collect your new passport. You get in line and realize that you have to wait for some time. You look around and see several other people waiting as well. Some are lost in their smartphones some are looking around. You remember your surprise encounter at the gate and wish you would have the heart to speak to one of the others waiting. Even though you had such a pleasant experience you feel too shy and hope for an incident that brings you in contact with somebody ...

Every situation has an inherent potential to produce positive emotions. As we just saw even a situation as awkward as waiting can evoke agreeable emotions if the constellation promotes it. This implies that every situation has the potential to be detected and harnessed. The present article addresses the question whether technology can facilitate situations which do not appear positive at first glance. Waiting times are a prime example for such situations. Waiting for the bus, at an airport gate, or waiting in waiting rooms of agencies or doctor's offices all have the potential to be experienced more positively. In this paper we will present a technological concept designed to initiate small talk in waiting situations in order to foster positive social experiences.

\subsection{Waiting Situations and the Possibility for Communication}

Previous research on waiting times have focused on analysing different waiting situations, reducing waiting time or improving waiting conditions (Durrande-Moreau and Usunier 1999; Nie 2000; Bournes and Mitchell 2002; Kutash and Northrop 2007; Minton 2008; Norman 2008; Zhou and Soman 2008; Ho et al. 2014; Asthana et al. 2015; Frank et al. 2015). The goal is to avoid letting waiting time negatively influence the perception of service providing people. Durrande-Moreau \& Usunier (1999, p. 180) showed that longer waiting times without feedback are unacceptable for customers, they become more impatient and dissatisfied.

Waiting typically leads to frustration and stress in the waiting person (Nie 2000). Therefore, researchers analyse waiting conditions and derive implications for service providers, for example, to inform customers about the effective waiting time (Nie 2000) or to arrange fair conditions in waiting lines (Norman 2008; Zhou and Soman 2008). Other studies deal with waiting in critical situations like waiting for relatives in hospitals (Bournes and Mitchell 2002; Kutash and Northrop 2007; Ho et al. 2014). Kutash and Northrop (2007) found that family members can find emotional support in the waiting room by talking to other waiting individuals. It became clear that sharing their thoughts with their companions in misfortune lightened their difficult situation. This study is one of the few that describes waiting time not only as annoying but also 
acknowledges a strength in the waiting situation namely deriving comfort from other relatives. Normally there is more than one person waiting. As Nie (2000, p. 612) notes "Since waiting involves people, time and environment, it is a social and psychological phenomenon." As demonstrated in the introductory example a possible resource of waiting situations is community. If there are other people present there is a possibility for communication and communication has positive effects: Higher well-being is positively correlated with time talking to others (Mehl et al. 2010). As we have learned sharing negative thoughts can have an easing effect, 'a problem shared is a problem halved' (Kutash and Northrop 2007). But on the other side, sharing positive thoughts can increase the effect of positive thoughts, too. Lambert et al. (2012) instructed their participants to write about a positive event from the past two weeks. Half of the group then had to share their experience with a romantic partner or a close friend. Participants in the sharing condition reported more positive affect and life satisfaction than participants who only wrote about their experience. The authors also showed that the effect is not ascribed to the sharing per se, but is referred to the sharing of a pleasant experience.

\subsection{Conversation: What Defines Small Talk?}

As we have seen, the positive effect of conversation with spouses as well as of communicating positive experiences is well documented. But, to our knowledge, what has been ignored are the topics 'talking to strangers' and 'small talk'.

In order to investigate the effects of these kinds of conversation we first have to understand their nature. There are only few articles concerning talking to strangers or small talk. The existing papers mainly come from communication research.

A theory addressing the communication to strangers is the anxiety/uncertainty management theory (AUM theory) (Gudykunst and Ting-Toomey 1988; Gudykunst 1998) which focuses on intercultural communication, but can be applied also to communication with strangers in situations within one culture (Duronto et al. 2005). The AUM theory states that when people can manage the uncertainty and the resulting anxiety the probability of effective communication between strangers of the same cultural group or intercultural groups increases. Uncertainty arises because of difficulties to predict and explain the mental state and behavior of unknown others. Based on uncertainty people anticipate negative consequences which results in an increase of anxiety. Avoidance of encounters and communication are the behavioural consequences of increased uncertainty and anxiety (Duronto et al. 2005). As a personality variable the theory on tolerance on ambiguity (TA) describes a continuum from tolerance to intolerance of ambiguous stimuli (Mclain 1993; Furnham and Marks 2013). An encounter with a stranger can be interpreted as an ambiguous situation. However, according to the AUM theory encounters with strangers create uncertainty, but it can be expected that persons with high tolerance of ambiguity will be less affected than people with low tolerance of ambiguity.

A possibility to communicate with a low level of uncertainty is small talk. Beinstein (1975, p 147) defines small talk as easy, effortless and friendly exchanges between both known and unknown persons. In particular, the ritualized and to a certain extent foreseeable process allows a routine handling even in unknown social encounters. Small talk allows us to establish social relationships, strengthens social cohesiveness and reduces fear of social contact. Furthermore it helps to structure social interactions 
and to define one's position in social community. Mehl et al. (2010) differentiate between small talk and substantial conversation. Whereas they see small talk as rather uninvolved and banal, substantive conversation in their view is of involved and substantive nature. They found that the amount of substantive conversation was amongst others positively correlated with socializing. Moreover, they found a negative correlation between well-being and the amount of small talk and a positive correlation between well-being and substantive conversation. This means that it is not only the amount of conversation but also the content that matters for well-being. Small talk normally revolves around safe topics (Coupland 2003) and signalizes a positive view on the conversation partner (Beinstein 1975). As Mehl et al. (2010) suggest it may be possible that happiness or well-being can be increased if people are provided with more possibilities to engage in conversations, especially in substantive conversations. At the same time substantive conversation entails the risk of refusal, which is why conversation partners have to have confidence in each other (Beinstein 1975). Two questions that arise from these considerations are: Is small talk better than no talk? Can technology be used to initiate small talk?

\subsection{Designing for Positive Experiences}

Our research asks if technology can be used to facilitate conversations or even to create possibilities to engage with other people. In their theory of 'Positive Technologies' Botella and Riva (2012) follow a similar approach with Positive Technology used on a social and interpersonal level. Thereby they refer to the concept of Positive Psychology (Seligman and Csikszentmihalyi 2000). Positive Psychology differs from classical psychological approaches in focusing positive aspects of life and not addressing compensation of deficits or solving problems. Positive Psychology seeks to find out what makes people happy and increases their well-being. For this purpose several strategies were developed (Lyubomirsky 2007; Seligman 2012) and their positive impact on various areas of life were affirmed (Fredrickson 2001; Kok et al. 2013). Botella and Riva (2012) transfer this theory to the use of technology and reflect how technology can be applied to enhance emotions, engagement and connectedness. Desmet and Pohlmeyer (2013) go into even more detail and explicitly investigate the effect design has on happiness and well-being which serves as a rough guideline for the concept of the present study. Positive Design is based on three pillars: Design for pleasure, personal significance and virtue. Experience design of Marc Hassenzahl (Hassenzahl 2010) focuses on designing experiences. According to this design approach positive user experience occurs through fulfilling psychological needs of people (Hassenzahl 2008, 2013).

Bringing people together via a technological device addresses the need for relatedness. Practical examples already exist (e.g. Kanis and Brinkman 2007), but most of them refer to the use of technology to communicate across large distances. The concept presented here is designed to make people talk what is assumed to make them feel good in waiting situations as it was the case for the character in the introductory example.

The starting point of the presented concept was the project IC-IC „Enhancing interconnectivity through infoconnectivity (GA 266250). In order to improve the travel experience of passengers on their way from a home location to a destination, a design process based on positive design and experience design has been developed (Burmester 
and Tille 2013). This includes the collection of positive experiences in the target activity in this case travelling. Respective interviews showed that spontaneous communication with other passengers in waiting situations are experienced in a very positive way. Based on these results a first concept of a vending machine supporting small talk was developed. This concept was further elaborated and worked out in a first prototype which was evaluated in a pre-study (Laib et al. 2014). According to the results of the study the concept of the Snackomat was finalized to its present status.

Based on the specified theoretical foundations and earlier research results we formulated two hypotheses. Both of them are based on the following elements: The IC-IC project showed that small talk in waiting situations cause positive experiences. We suppose that the positive emotions related to the conversation experience are based on the fulfilment of the need for relatedness. According to the AUM theory people feel ambiguous and uncertain when confronted with strangers which normally leads to anxiety and avoidance of communication. The vending machine is designed to initiate small talk by bringing people together in front of the vending machine and by providing save conversation themes on snack selection and snack attributes.

(1) People will feel better after a waiting situation with a machine designed to initiate small talk than after a waiting situation with a reference technology not explicitly designed to initiate small talk like a coffee machine.

(2) People will rate the quality of the waiting situation with a machine designed to initiate small talk better than the waiting situation with a reference technology not explicitly designed to initiate small talk like a coffee machine.

The study has the character of a pilot study as we are not aware of many studies designing a technology to improve waiting experiences and test it in a laboratory setting.

\section{Method}

\subsection{Participants}

The sample was divided into two subgroups. The experimental group was investigated in a waiting situation with the Snackomat, the control group waited in a room with a coffee machine. 59 participants took part in the study, one participant recalled the use of all of his data. The remaining 58 participants were divided equally across the two groups. There were no differences between the two groups according to gender, $\chi^{2}(1)=0.07, p=.79$ (Snackomat: 16 women, coffee machine: 17 women), according to age, $\mathrm{t}(56)=-.61, p=.55$ (Snackomat: $\mathrm{M}=23.21, \mathrm{SD}=3.81$, coffee machine: $\mathrm{M}=$ 23.76, $\mathrm{SD}=3.10$ ), according to education, $\chi^{2}(1)=1.80, p=.18$ (Snackomat: 20 with general qualification for university entrance and 9 with graduate degree, coffee machine: 15 with general qualification for university entrance and 12 with graduate degree). Both conditions Snackomat and Coffee Machine had the same group structure: six groups with four, one group with three and one group with two waiting people. As one participant did not give his consent to use any of his data in the study, one video of four participants had to be deleted, one other participant refused to give consent to use 
his video data. He was in a waiting group with one other person, which is why the video data of those two participants was deleted as well. One other participant preferred to wait outside of the waiting room. Therefore the video analysis comprised only the data of 52 participants.

Participants were recruited through advertisements posted in buildings of the University of Stuttgart and the Stuttgart Media University. To keep participants blind to the study's objective the research was announced as a group discussion with 4 people at a time about new technologies. It was said that participants should not know each other. Participation was compensated with $20 €$ or research credits.

\subsection{Artefacts}

\subsubsection{Prototype of the Snackomat}

Briefly summarized the Snackomat is a vending machine offering snacks for free. It is conceptualized to be installed in waiting situations (e.g. doctor's waiting room). The prototype of the Snackomat (Fig. 1) consists of one large 47" touch screen display, a coin slot detector, a motor with a screw propulsion and an Arduino microprocessor hub to negotiate between the parts. A visual interface application written in Java, records both the user input on the touch screen and how many coins have been inserted. It also computes the interaction concept ideas concerning the waiting time, the time to press the buttons, and the whole user interface procedures. Depending on the case, it delivers corresponding signals to the Arduino, which controls the motor and the necessary rotations of the screw propulsion to transport the snacks to the output tray. If all snacks are delivered, another loop is initiated. The vending machine dispenses exotic snacks.

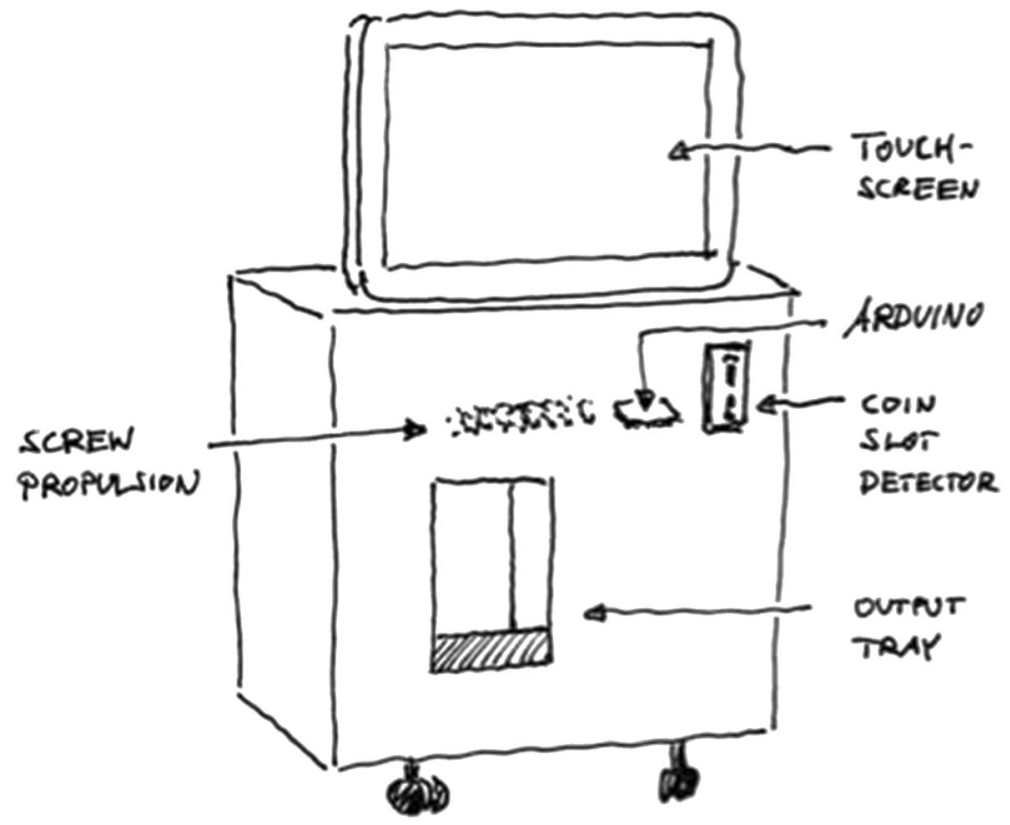

Fig. 1 Prototype of the Snackomat 
These are from different countries (e.g. Mexico, Poland) and Germans are not familiar with these candies.

Ordinary snack vending machines are designed to deliver snacks in an efficient manner. People interested in a snack, can just use the vending machine to get it. A conversation with other people is not intended and could just happen by chance. The Snackomat is different. Its main purpose is to encourage people to start small talk and to enjoy the conversation and interactions with others in waiting situations. Consequently, the principles of the Snackomat design were the following:

- According to early research, proximity of people turned out to be an important prerequisite for initiation of communication with strangers (Sykes 1983). Therefore, several design decisions were made to bring people together in front of the vending machine.

- According to the AUM theory (Gudykunst 1998; Duronto et al. 2005) it is necessary to reduce uncertainty in order to initiate communication. This is done in several ways: a) building a group by connecting the delivery of snacks to a group of persons, b) providing safe communication themes in order to initiate small talk (e.g. asking others whether they like to have a snack, presenting interesting information concerning the snacks, giving small puzzles to initiate conversation on finding out information).

- Drawing attention from coping with the individual waiting situation (e.g. reading messages in the smartphone) to the Snackomat (e.g. by acoustic signals indicating that a snack can be ordered).

- The Snackomat offers possibilities for starting communication to others in the waiting situation, but the decision whether a person wants to participate is up to the persons in the waiting situation. The idea was that all waiting persons could decide to wait with or without communication to others.

Figure 2 gives an impression how a waiting situation inclusing the Snackomat could look like: People are waiting and two strange people are already gathering around the
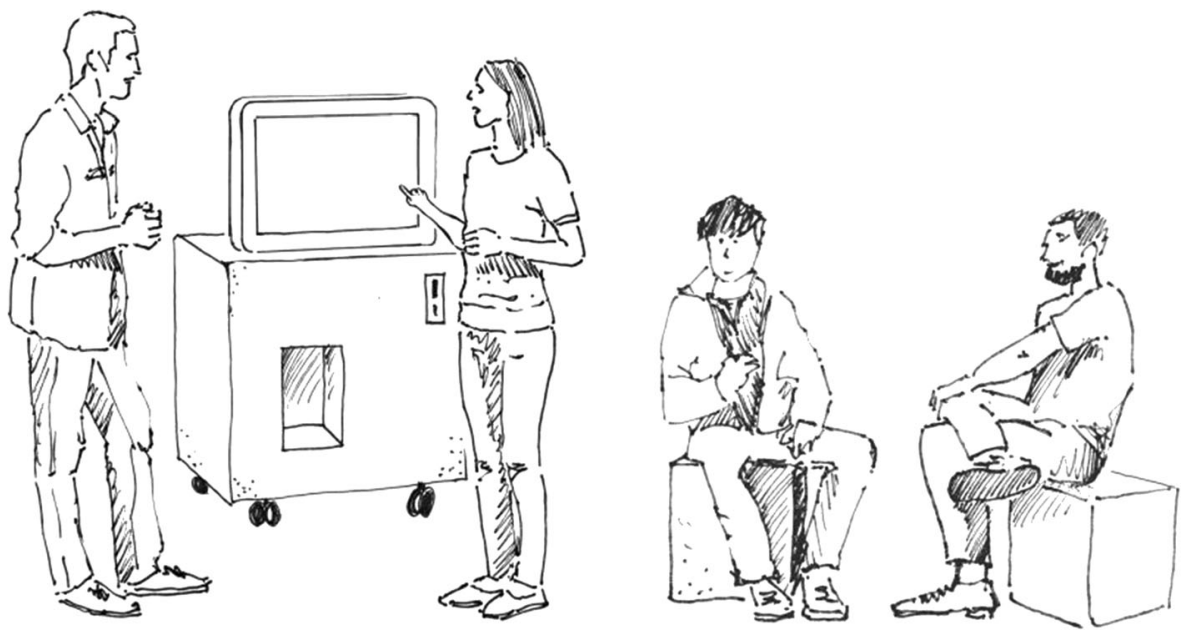

Fig. 2 Visualisation of the waiting situation including the Snackomat 
vending machine interacting together to get free snacks. Table 1 gives an overview over the individual components of the Snackomat and their Design Rationales. A Design Rationale explains what is intended by the designs. To illustrate the design of the vending machine we show corresponding screens. In addition to that, we present and describe the snack design as part of the overall design concept.

When participants entered the waiting situation they received coins (Table 1, Line 1). The Snackomat ran in cycles of offering snacks. If one cycle was completed, the next cycle began automatically. Besides the emission of the snacks, every step of the dispensing procedure was shown on the screen of the vending machine. One cycle started with a 5-min countdown (see Table 1, Line 2). During the countdown the screen slowly filled with a second colour. When the countdown ended, the screen had changed

Table 1 Description of the prototype of the Snackomat

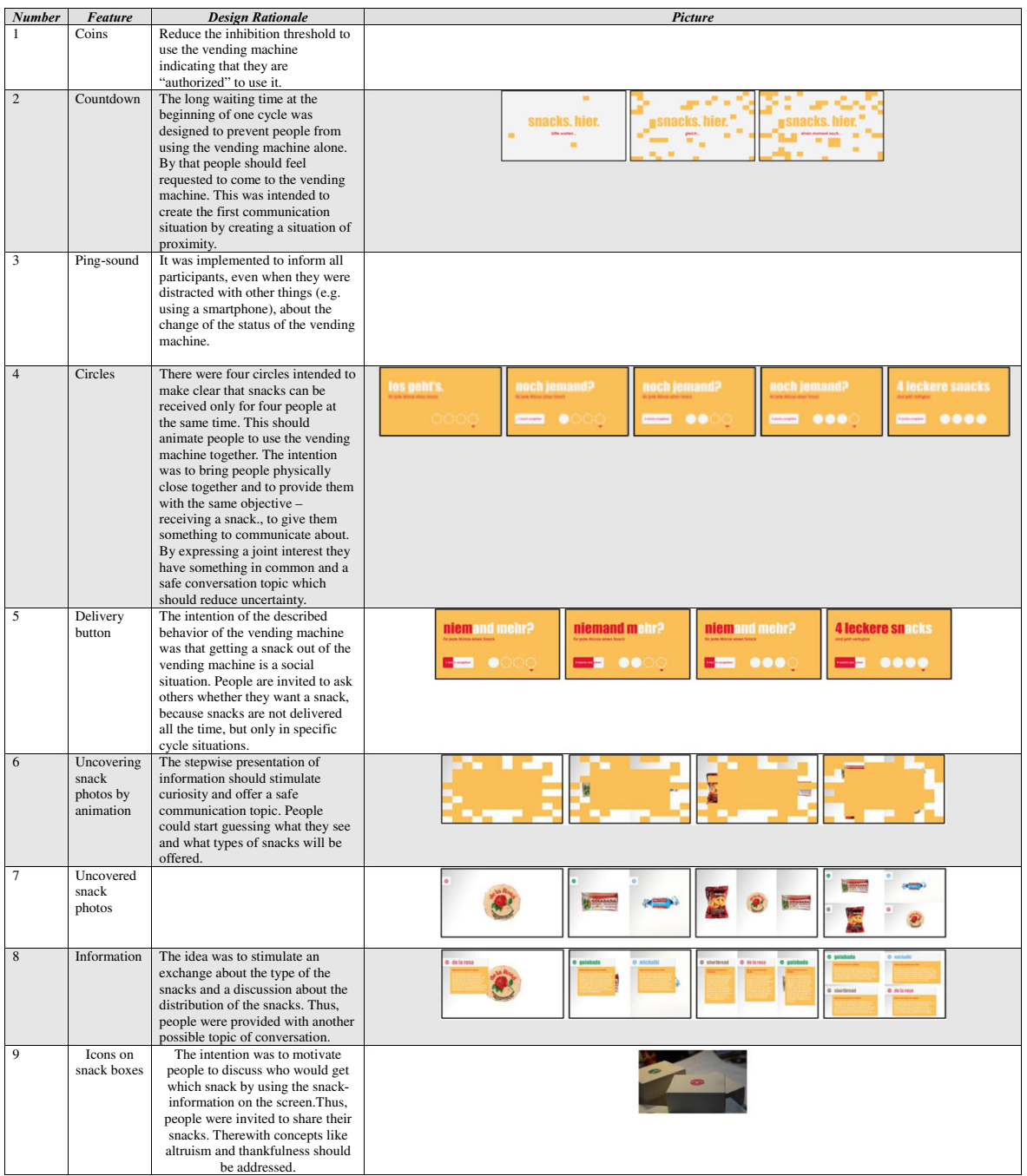


from white to orange. At the beginning of the countdown the wording said "snacks, here. please wait ...", after $100 \mathrm{~s}$ the wording changed to "snacks, here. soon ..." and after another $100 \mathrm{~s}$ to "snacks, here. just a moment ..." . After $5 \mathrm{~min}$ a ping-sound indicated the end of the countdown (see Table 1, Line 3). Participants were then asked to insert their coins. On the screen four circles (see Table 1, Line 4) representing coins were depicted reading: "Get going, every coin one snack". A red arrow pointing to the coin slot flashed every 600 milliseconds. If one coin was inserted one circle filled and the wording changed to "Anybody else? Every coin one snack". Additionally a button appeared with the label "Dispense 1 snack". The number on the button corresponded to the number of coins previously inserted. If people wanted their snack to be delivered they had to press the button (see Table 1, Line 5). The idea was that people had to press the button for $2.6 \mathrm{~s}$, until it had 'filled' with red. If less than 4 coins were inserted the wording on the top of the screen changed from "Anybody else? Every coin one snack" to "Nobody else? every coin one snack", while the words also filled with red colour.

When the desired number of snacks was requested, the screen changed colours over two minutes to complete orange while, little by little, revealing pictures of the snacks (animation, see Table 1, Line 6). At the end of the animation people saw photos of the snacks (see Table 1, Line 7), the quantity corresponded to the number of inserted coins. After $1.5 \mathrm{~s}$ a coloured icon appeared and flashed every 500 milliseconds until it was touched. By clicking on the coloured icon people could access additional information about the snacks (see Table 1, Line 8). Pressing the icon again the information disappeared. If no icon was clicked for the time of one minute the snack photos slowly faded out and the countdown screen appeared again. This change took one minute. This was intended to indicate that the machine would remove the information screen so that interested participants had the possibility to decide to read the snack information before it is gone. As previously mentioned, every photo was furnished with a coloured icon. At the end of one cycle snacks were dispensed in boxes. Every box was also marked with a coloured pictogram similar to the icon and could therefore be assigned to one snack (see Table 1, Line 9). The snacks offered are rather exotic snacks (e.g. sweets from Mexico or Poland) and they are always different, so that people get curios about the taste. They could start to let other persons taste their snack and they could talk about the different tastes and snack origins. By creating simple and safe conversation topics the probability of small talk should increase. Furthermore, the need for stimulation could be fulfilled by the exotic snacks and its background information. Finally, the taste of the snacks could cause an additional positive experience in the waiting situation.

\subsubsection{Coffee Machine}

The coffee machine was a Nespresso coffee machine (see Fig. 3). An ordinary coffee machine is designed to offer coffee. Even it is not designed for initiating conversation, it is possible that when a person uses a coffee machine it makes it more likely that other persons follow the lead. This means that the use of the coffee by one person increases its use by other persons. Furthermore, it is comparable to the Snackomat in that it also is necessary that people have to go there to get coffee and probably meet at the coffee machine. It is interactive because of inserting coffee capsules and pressing buttons to choose and start, as well as it dispenses a food product offered in variations because different coffee flavors could be chosen. In general it would be possible to ask other 


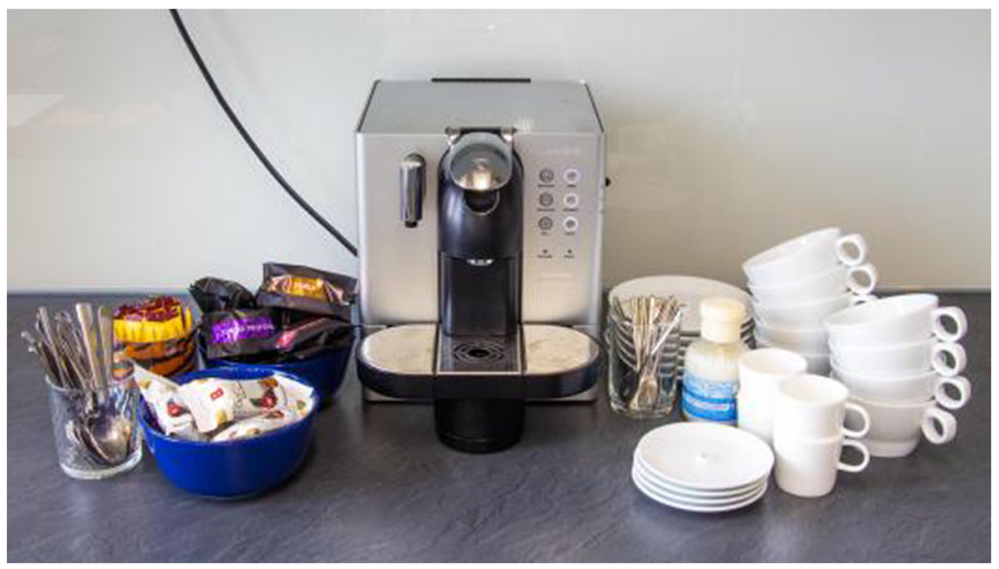

Fig. 3 Coffee machine

waiting people whether they want a cup of coffee and that the asking person could prepare it for another person in order to start a conversation. Offering just newspapers or magazines, would not be an appropriate control condition, because this activity draws the attention explicitly away from other persons in waiting situations and is very self-oriented.

\subsection{Measurement and Data Acquisition}

To measure relevant data we fell back on existing instruments to measure positive and negative affect (PANAS, Watson et al. 1988), needs fulfilled through the use of the technology (UneeQ, Fronemann and Peissner 2014) and personality variables (NEOFFI, Costa and McCrae 1992). Furthermore, the following questions were derived from the theory section: momentary feeling of happiness, evaluation of waiting time, evaluation of conversations, evaluation of the technology, observed behaviour (video analysis) and questions controlling for the study design as suspicions about the study's objective and acquaintanceship with other participants.

To improve clarity we numbered every variable. These numbers are taken up in the results section.

\subsubsection{Positive and Negative Affect}

To measure whether there was a difference in mood between the two groups after the waiting situation the Positive and Negative Affect Schedule (PANAS, Watson et al. 1988; German: Krohne et al. 1996) was used. The PANAS consists of 20 adjectives, 10 adjectives measuring positive affect and 10 adjectives measuring negative affect. Answers are given on a 5-point Likert-scale. Cronbach's $\alpha$ was $\alpha=.85$ for the positive affect scale, which argues for a good reliability of the scale (Field 2013). Cronbach's $\alpha$ for the negative affect scale was $\alpha=.70$, which is slightly below the desired value. With the PANAS we thus assessed two variables (1) positive affect and (2) negative affect. Validity of PANAS is confirmed in Krohne et al. (1996) . 


\subsubsection{Momentary Feeling of Happiness}

Using a visual analogue scale (inspired by Russell et al. 1989; Bradley and Lang 1994; Abdel-Khalek 2006), participants had to rate how happy they felt 'at this moment'. The scale ranged from 'not happy at all' to 'very happy'. (3) The amount of happiness was operationalized as the distance from the lower end of the scale to the set mark of the participant.

\subsubsection{Evaluation of Waiting Time, Conversations and the Technology}

A questionnaire was designed to capture different aspects of the waiting situation. It consisted of three parts and in general answers were given on a 5-point Likertscale .

Waiting Time In the first part participants were asked to judge the waiting situation (estimated time, positive utilization, perceived duration). If they had conversations during the waiting time, people were asked to rate how they had liked the conversations, how much they had talked and if they had felt shy about talking to the other participants. At the end of the first part they were asked whether they had used the Snackomat (or respectively the coffee machine) and how many people had joined them (none, 1, 2 or 3). Four aspects were analysed with this part of the questionnaire: (4) Estimated duration of the waiting time, as some participants had arrived too late, the estimated duration was relativized on the actual duration of waiting time (5) Positive utilization of the waiting time: A mean value was calculated for the items "I think the waiting situation was agreeable", "The waiting time appeared very long" (reverse scored), "I think the conversation(s) during the waiting time were agreeable", "I have talked a lot during the waiting time" and "I shied away from talking to the other participants" (reverse scored), Cronbach's $\alpha$ was $\alpha=.76$, (6) Use of the respective technology: Did participants actually use the technology, (7) Number of persons involved in technology use.

Conversations The second part of the questionnaire dealt with the conversations conducted during the waiting time. Participants had to evaluate, if the Snackomat (or respectively the coffee machine) had made it easier to start a conversation and if the technology had been topic of their conversations. They were asked, how superficial the conversations had been, whether they would have preferred deeper conversation topics, whether they had liked talking to others or whether they would have preferred to stay alone. Four scores were calculated: (8) Mean score of the positive influence of the technology on conversation using the items "The machine made it easier for me to start a conversation", "The machine was topic of my conversations", Cronbach's $\alpha$ was $\alpha=.81$ (9) Were the conversations defined as small talk using the item "The topics of the conversation were rather superficial (small talk)", (10) Did the depth of the conversation correspond to the users needs using the items "I would have preferred conversations with more depth", (11) Agreeableness of the conversations using the following items: "I would have preferred to stay by myself than to talk" (reverse scored), "It was agreeable to talk to the other waiting people", Cronbach's $\alpha$ was $\alpha=.62$. 
Technology In the third part of the questionnaire, the technology itself (Snackomat or coffee machine) was evaluated. Participants had to rate the attractiveness of the vending or the coffee machine, whether it had positively influenced the positive utilization of the waiting time and if the possibility to be used by several people had frightened them. One mean score was calculated representing the (12) positive influence of the machine on the waiting time using the items "I perceived the machine as annoying" (reverse scored), "The machine brought me joy", "The machine peaked my interest", "The machine made me perceive the waiting time as agreeable", "The machine made me perceive the waiting time as disagreeable" (reverse scored), "It scared me that several people could use the machine at once" (reverse scored), Cronbach's $\alpha$ was $\alpha=.84$.

\subsubsection{User Needs}

To assess which needs were fulfilled through the use of the technology the User Needs Questionnaire (UneeQ, (Fraunhofer-IAO 2014; Fronemann and Peissner 2014) was implemented. It consists of five items measuring the (13) overall User Experience (Cronbach's $\alpha=.82$ ) and 30 items referencing on ten different psychological needs: (14) Security (Cronbach's $\alpha=.67$ ), (15) Collecting meaningful things (Cronbach's $\alpha=.79$ ), (16) Self-expression (Cronbach's $\alpha=.59$ ), (17) Relatedness (Cronbach's $\alpha=.72$ ), (18) Popularity (Cronbach's $\alpha=.78$ ), (19) Competition (Cronbach's $\alpha=.89$ ), (20) Physical health (Cronbach's $\alpha=.62$ ), (21) Competence (Cronbach's $\alpha=.66$ ), (22) Influence (Cronbach's $\alpha=.62$ ), (23) Stimulation (Cronbach's $\alpha=.84$ ). Answers are given on a five-point Likert-scale. The questionnaire is based on the frameworks of Reiss and Havercamp (1998), Ryan and Deci (2000) and Sheldon et al. (2001) and refers to the framework of Hassenzahl et al. (2010).

\subsubsection{Video Analysis}

In addition to the questionnaires the videos of the waiting situations were analyzed. Therefore the videos were imported to Observer (Noldus 2010) with what frequency and duration of different variables were measured individually for each participant: (24) Total duration of talking time, (25) number of changes of speakers, (26) number of times participants told something personal, (27) number of times participants talked about the technology, (28) number of times participants talked about anything else (not about the machine or about themselves), (29) number of times participants expressed suspicion about the study's objective, (30) number of times participants talked about the waiting time (positive or negative), (31) type of statement about the waiting time: the statement was rated according to its valence $(-1$ - negative, 0 - neutral, 1 positive), (32) duration of time participants used other items (e.g. smartphone, magazine), (33) number of laughs, (34) Intensity of laugh: 1 - Smiling loudly, 2 - Utter a brief laugh, 3 - Laughing loudly and heartily.

\subsubsection{Control Variables}

Study This part of the experiment was evaluated to control the study's circumstances. Four aspects were analysed: (1) Observation of the waiting situation, using the item "I 
sensed that the waiting situation was observed", (2) Investigation of the Snackomat using the item "I sensed that the Snackomat was investigated", (3) Objective of the study using the item "I sensed that the objective of the Snackomat was to bring the waiting people into contact", (4) Acquaintanceship: Did the participants know each other in advance.

Personality Variables To control for differences in personality affecting differences between the two groups we used the German version (Borkenau and Ostendorf 2008) of the Neo Five-Factor inventory (NEO-FFI, Costa and McCrae 1992). It consists of five scales measuring Extraversion, Agreeableness, Conscientiousness, Neuroticism, and Openness to Experience. For the present study we choose three out of the four scales as they are assumed to have the greatest influence on addressing other people: Extraversion (Cronbach's $\alpha=.68$ ), Neuroticism (Cronbach's $\alpha=.81$ ), and Openness to Experience (Cronbach's $\alpha=.70)$. The NEO-FFI is a widely used questionnaire to assess personality variables and is validated in various studies (e.g. Körner et al. 2002).

\subsection{Procedure}

The ethical committee of the German association for Psychology approved the study protocol. Via email or telephone four participants were advised to meet at the appointed hour in front of the authors' office. Due to illness or cancellation some study groups were smaller ( 2 or 3 people). Table 2 depicts the procedure for both conditions. The composition of the room was the same in both conditions except for the respective technology. There were enough chairs for everyone to sit.

\subsection{Statistical Analysis}

In order to examine whether potentially confounding variables were equally distributed over the two study conditions, Chi-Square-Tests or t-Tests were calculated. Correlations between control variables and dependent variables were calculated with Pearson's correlation coefficient $(r)$ or Spearman's rank correlation coefficient $\left(\mathrm{r}_{\mathrm{s}}\right)$.

Controlling for an interval-scaled control variable that fulfilled the preconditions to be included as a covariate according to Miller and Chapman (2001), we ran an analysis of covariance (ANCOVA) in a second step.

Comparing the two conditions we calculated multiple t-Tests and corrected alpha levels (Bonferroni) to control for alpha error inflation. As we ran $34 \mathrm{t}$-Tests, the alpha level was reduced to $p=.001\left(\mathrm{P}_{\mathrm{Crit}}=\alpha / k, \alpha=.05, k=\right.$ number of comparisons, Field 2013).

\section{Results}

\subsection{Control Variables}

When faced with the Snackomat condition participants were more likely to believe that the objective of the study was to make people talk to each other. Although they were aware of the observation, the analysis of the videos revealed that the conversation on 
Table 2 Study procedure

\begin{tabular}{|c|c|c|c|}
\hline Number & Step & Snackomat condition & Coffee machine condition \\
\hline 1 & $\begin{array}{l}\text { Welcome and } \\
\text { cover story }\end{array}$ & \multicolumn{2}{|c|}{$\begin{array}{l}\text { When all participants had arrived the experimenter went out and told them that } \\
\text { the beginning of the discussion had been delayed. They were told that the } \\
\text { other group had started later because one participant had arrived late but } \\
\text { they were assured that the study did not need as much time as expected and } \\
\text { that their discussion would finish in time. Then the experimenter asked } \\
\text { them to wait and offered them a room. }\end{array}$} \\
\hline 2 & $\begin{array}{l}\text { Reason for } \\
\text { technology in } \\
\text { the room }\end{array}$ & $\begin{array}{l}\text { Participants were told that one of the } \\
\text { study courses had brought a } \\
\text { prototype of a vending machine } \\
\text { that other people could use. } \\
\text { Therefore, the experimenter } \\
\text { offered the participants to test the } \\
\text { prototype while waiting. The } \\
\text { experimenter pretended to not } \\
\text { know the Snackomat. }\end{array}$ & $\begin{array}{l}\text { In the coffee machine condition } \\
\text { participants were told that some } \\
\text { employees just had finished a } \\
\text { workshop and that they had left the } \\
\text { coffee machine in the room. The } \\
\text { experimenter offered them to wait } \\
\text { in this room and to get some coffee } \\
\text { while waiting. }\end{array}$ \\
\hline 3 & Coins & $\begin{array}{l}\text { The experimenter handed each } \\
\text { participant one coin. }\end{array}$ & $\begin{array}{l}\text { No coins. Free access to coffee } \\
\text { machine and necessary ingredients. }\end{array}$ \\
\hline 4 & Leaving the room & \multicolumn{2}{|c|}{$\begin{array}{l}\text { Promising to collect them up as soon as the other group had finished their } \\
\text { group discussion he then left the waiting room. }\end{array}$} \\
\hline 5 & Observation & \multicolumn{2}{|c|}{$\begin{array}{l}\text { Unknown to the participants, the 'waiting room' was a lab and the whole } \\
\text { waiting situation was video recorded. In both conditions participants } \\
\text { remained in the waiting room for } 25 \mathrm{~min} \text {. }\end{array}$} \\
\hline 6 & $\begin{array}{l}\text { Resolving the } \\
\text { situation }\end{array}$ & \multicolumn{2}{|c|}{$\begin{array}{l}\text { After the waiting time } 2 \text { experimenters entered the waiting room. One } \\
\text { experimenter took two of the participants to another room the other } \\
\text { experimenter stayed with the other two participants. They were shortly } \\
\text { debriefed and told that the waiting situation was under research and that no } \\
\text { group discussion would take place. }\end{array}$} \\
\hline 7 & Questionnaires & \multicolumn{2}{|c|}{$\begin{array}{l}\text { They were first asked to first fill out the questionnaires (PANAS, Momentary } \\
\text { feeling of happiness, Evaluation of waiting time, conversations, automat } \\
\text { and study, NEO-FFI, Sociodemographic variables), then to sign the } \\
\text { informed consent. }\end{array}$} \\
\hline 8 & Debriefing & \multicolumn{2}{|c|}{$\begin{array}{l}\text { Afterwards they were fully debriefed and given the possibility to ask further } \\
\text { questions. }\end{array}$} \\
\hline
\end{tabular}

their suspicion was rather short in all experimental groups and had a hardly impact on the content of conversation. Three people in the Snackomat condition and two people in the control condition knew each other in advance (for test statistics see Table 3).

Four variables were considered as potential covariables, the three personality variables Extraversion, Neuroticism and Openness to Experience as well as the study variable observation of the waiting situation, using the item "I sensed that the waiting situation was observed". The two groups did not differ according to Extraversion $(t(56)=0.21, p=.84$, Snackomat: $M=40.66, S D=5.56$, coffee machine: $M=40.31$, $S D=6.91)$, Neuroticism $(t(56)=-0.05, p=.96$, Snackomat: $M=32.00, S D=7.04$, coffee machine: $M=32.10, S D=7.68)$ and Openness to Experience $(t(56)=0.71$, $p=.48$, Snackomat: $M=43.14, S D=5.65$, coffee machine: $M=41.97, S D=6.92$ ). However, as mentioned above, there was a difference according to the assumed observation of the waiting time. Accordingly, the variable observation of the waiting 
Table 3 Statistics of the control variables examining the transparency of the study and previous acquaintanceships

\begin{tabular}{|c|c|c|c|c|c|c|c|}
\hline \multirow[t]{2}{*}{ Variable } & \multirow[t]{2}{*}{$\mathrm{T}$} & \multirow[t]{2}{*}{ df } & \multirow[t]{2}{*}{ Sig. } & \multicolumn{2}{|c|}{ Snackomat } & \multicolumn{2}{|c|}{ Coffee machine } \\
\hline & & & & M & $\mathrm{SD}$ & M & SD \\
\hline (1) Observation of the waiting situation & 2.25 & 56 & $.028 *$ & 3.62 & 1.40 & 2.72 & 1.62 \\
\hline (2) Investigation of the Snackomat & 8.76 & 42.10 & $<.001 * * *$ & 3.71 & 1.27 & 1.31 & 0.71 \\
\hline (3) Objective of the study & 2.50 & 56 & $.016^{*}$ & 2.66 & 1.29 & 1.86 & 1.13 \\
\hline Variable & $x^{2}$ & $\mathrm{df}$ & Sig. & Yes & No & Yes & No \\
\hline (4) Acquaintanceship & .22 & 1 & .640 & 3 & 26 & 2 & 27 \\
\hline
\end{tabular}

Notes 1. *** $p<.001, * * p<.01, * p<.05$.

situation might not be considered as a covariable. We correlated the three NEO-FFI variables with the 34 dependent variables (see Table 4). Whenever a correlation was significant we considered the respective variable as a covariate in the main analysis.

\subsection{Main Analyses}

The results of all comparisons can be seen in Table 5. To improve clarity comparisons in Table 5 are sorted according to their effect size (high to low). At the beginning we report the results as they showed with applying Bonferroni correction.

First participants were given the PANAS to see if the two groups differed in their positive or negative affect. There was no significant difference between the two groups, neither in (1) positive nor (2) negative affect. ${ }^{1}$

Next, people were asked to indicate their (3) momentary feeling of happiness. We found no significant difference between the two groups. ${ }^{2}$

Following this, participants were given a questionnaire to evaluate the waiting situation they had just experienced. Participants in the Snackomat condition perceived the (4) duration of the waiting time as significantly shorter than participants in the control condition. There was no difference in the (5) positive utilization of the waiting time. Participants (6) used the provided technology (in this case the Snackomat) significantly more often (29 times) than participants in the control condition used the coffee machine (10 times). There was no difference in the (7) number of persons who were involved in the use of the technology.

Participants were also asked to evaluate the conversations they had with the other waiting participants. The Snackomat had a significantly (8) greater positive influence on the conversations than the coffee machine. Furthermore, in the Snackomat condition (9) conversations were defined as small talk more often than in the control condition. Participants did not prefer more (10) depth in their conversations in either of the two conditions and did not rate the (11) agreeableness of the conversations differently.

\footnotetext{
${ }^{1}$ Including extraversion as a covariate did not change the results, $F(1,55)=0.08, p=.782$.

${ }^{2}$ Including extraversion as a covariate did not change the results, $F(1,54)=0.19, p=.667$.
} 
Table 4 Correlations between NEO-FFI variables neuroticism, extraversion and openness to experience and the dependent variables

Dependent variables

Personality variables

Neuroticism Extraversion Openness

to Experience

(1) Positive affect

(2) Negative affect

(3) Amount of happiness

(4) Estimated duration of waiting time

(5) Agreeableness of waiting time

(6) Use of the respective technology

(7) Number of persons involved in technology use

(8) Positive influence of the technology on conversation

(9) Conversations defined as small talk

(10) Depth of the conversation correspond to the users needs

(11) Agreeableness of conversations

(12) Positive influence of the automat on the waiting time

(13) UneeQ: Overall User Experience

(14) UneeQ: Security

(15) UneeQ: Collecting meaningful things

(16) UneeQ: Self-expression

(17) UneeQ: Relatedness

(18) UneeQ: Popularity

(19) UneeQ: Competition

(20) UneeQ: Physical health

(21) UneeQ: Competence

(22) UneeQ: Influence

(23) UneeQ: Stimulation

$$
\begin{aligned}
& r=-.01, \quad r=.30, \quad r=.22, p=.104 \\
& r=.17, p=.196 \quad r=-.10, \quad r=-.16 \text {, } \\
& p=.468 \quad p=.238 \\
& r=-.18, \quad r=.28, \quad r=.09, p=.499 \\
& p=.167 \quad p=.033^{*} \\
& r=.08, p=.561 \quad r=-.20, \quad r=-.03 \text {, } \\
& p=.150 \quad p=.846 \\
& r=-.09 \text {, } \\
& p=.502 \\
& r_{s}=-.02 \text {, } \\
& p=.859 \\
& r=.21, p=.115 \\
& r=.13, p=.319 \\
& r=.12, p=.464 \\
& r_{s}=-.10 \text {, } \\
& p=.484 \\
& r_{s}=-.11 \text {, } \\
& p=.429 \\
& r=-.16 \text {, } \\
& p=.330 \\
& r=.11, p=.452 \quad r=-.07, \\
& r=-.14 \text {, } \\
& p=.312 \\
& r=-.16 \text {, } \\
& p=.265 \\
& r=-.05 \text {, } \\
& p=.724 \\
& r=.02, p=.902 \\
& r=.10, p=.485 \\
& r=.06, p=.655 \\
& r=-.09 \text {, } \\
& p=.523 \\
& r=-.07 \text {, } \\
& p=.635 \\
& r=-.18 \text {, } \\
& p=.177 \\
& r=.20, p=.169 \quad r=-.15 \text {, } \\
& p=.306 \\
& r=.21, p=.149 \\
& r=-.03 \text {, } \\
& p=.833 \\
& r=.10, p=.453 \\
& r=.06, p=.658 \\
& r=.06, p=.654 \\
& r=-.06 \text {, } \\
& p=.675 \\
& r=.17, p=.227 \quad r=.11, p=.450 \\
& r=.14, p=.317 \quad r=-.14 \text {, } \\
& p=.310 \\
& r=.11, p=.432 \\
& r=.17, p=.220 \\
& r=-.01 \text {, } \\
& p=.972 \\
& r=.06, p=.672 \\
& r=.18, p=.184 \\
& r=-.02 \text {, } \\
& p=.865 \\
& r=-.04 \text {, } \\
& p=.747 \\
& r=-.06 \text {, } \\
& p=.686 \\
& r=.11, p=.421 \\
& r=.05, p=.706 \\
& r=.16, p=.222 \\
& r=-.02 \text {, } \\
& p=.900 \\
& r=.04, p=.788 \\
& r=.07, p=.611 \\
& r=.07, p=.621 \\
& p=.919 \\
& r=.11, p=.402 \quad r=.17, p=.208 \quad r=.04, p=.785 \\
& r=.17, p=.197 \quad r=.20, p=.130 \quad r=.08, p=.545 \\
& r=-.09 \text {, } \\
& p=.510 \\
& r=.08, p=.556 \quad r=.03, p=.853
\end{aligned}
$$


Table 4 (continued)

Dependent variables

Personality variables

\begin{tabular}{lll}
\hline Neuroticism $\quad$ Extraversion & $\begin{array}{l}\text { Openness } \\
\text { to Experience }\end{array}$
\end{tabular}

(24) Total duration of talking time

(25) Number of changes of speakers

(26) Number of times participants told something personal

(27) Number of times participants talked about the technology

(28) Number of times participants talked about anything else (not about the automat or about themselves)

(29) Number of times participants expressed suspicion about the study's objective

(30) Number of times participants talked about the waiting time (positive or negative)

(31) Type of statement about the waiting time

(32) Duration of time participants used other items (e.g. smartphone, magazine)

(33) Number of laughs

(34) Intensity of laugh

$$
\begin{aligned}
& r=-.24 \text {, } \\
& p=.079 \\
& r=-.08 \text {, } \\
& p=.571 \\
& r=.05, p=.720 \quad r=.21, p=.130 \\
& r=-.23 \text {, } \\
& p=.095 \\
& r=-.12 \text {, } \\
& p=.384 \\
& r=-.20 \text {, } \\
& p=.163 \\
& r=.09, p=.518 \quad r=-.19, \\
& r=.34 \text {, } \\
& r=.19, p=.168 \\
& \begin{aligned}
r=.06, p=.672 \quad r=.32, \\
p=.019 *
\end{aligned} \\
& r=.04, p=.788 \quad r=.15, p=.298 \\
& r=.19, p=.186 \quad r=.24, p=.089 \\
& r=.05, p=.718 \quad r=.13, p=.356 \\
& p=.013^{*} \\
& r_{s}=-.09, \quad r_{s}=.37, p=.041 \quad r_{s}=-.04, \\
& p=.638 \quad p=.851 \\
& r=.26, p=.067 \quad r=.01, p=.955 \quad r=-.18 \text {, } \\
& p=.206 \\
& r=-.03, \\
& p=.831 \\
& r=.05, p=.701 \quad r=.06, p=.677 \\
& r=.04, p=.805 \quad r=.19, p=.222 \quad r=.16, p=.301
\end{aligned}
$$

Notes. $* * * p<.001, * * p<.01, * p<.05$

The evaluation questionnaire ended with an evaluation of the respective technology. In the Snackomat condition the technology had a significant (12) greater positive influence on the waiting time than in the control condition.

With the help of the UneeQ the overall User Experience was measured as well as the individual needs the respective technology fulfils. The (13) overall User Experience of the Snackomat was rated significantly better that that of the coffee machine. In addition the Snackomat was perceived as significantly more (23) stimulating than the coffee machine. There were no differences between the two conditions in (14) security, (15) collecting meaningful things, (16) self-expression, (17) relatedness, (18) popularity, (19) competition, (20) physical health, (21) competence and (22) influence.

Additionally to the analysis of the questionnaires, the videos were analysed as well. Participants in the Snackomat condition (27) talked significantly more about the technology in the room than in the control group. There was no difference between the two conditions in the (24) total duration of talking and in (25) how often participants alternated speaking. Participants did not differ in the (26) number of times they mentioned something personal, in the (28) number of times they talked about anything else (not about the machine or about themselves), in the (29) number of times they 
Table 5 Statistics of the variables comparing Snackomat and coffee machine (ordered by effect size d: high, medium, low separated by dashed lines)

\begin{tabular}{|c|c|c|c|c|c|c|c|c|}
\hline \multirow[t]{2}{*}{ Variable } & \multirow[t]{2}{*}{$\mathrm{T}$} & \multirow[t]{2}{*}{ df } & \multirow[t]{2}{*}{ Sig. } & \multirow[t]{2}{*}{$\mathrm{d}$} & \multicolumn{2}{|c|}{ Snackomat } & \multicolumn{2}{|c|}{ Coffee machine } \\
\hline & & & & & M & SD & M & SD \\
\hline $\begin{array}{l}\text { (8) Positive influence of the technology } \\
\text { on conversation }\end{array}$ & 9.40 & 50 & $<.001 * * *$ & 2.590 & 3.90 & 0.72 & 1.76 & 0.92 \\
\hline $\begin{array}{l}\text { (27) Number of times participants } \\
\text { talked about the technology }\end{array}$ & 7.52 & 30.98 & $<.001 * * *$ & 1.986 & 16.45 & 10.41 & 1.52 & 2.15 \\
\hline $\begin{array}{l}\text { (12) Positive influence of the automat } \\
\text { on the waiting time }\end{array}$ & 6.06 & 55 & $<.001 * * *$ & 1.592 & 4.15 & 0.62 & 3.08 & 0.72 \\
\hline (13) UneeQ: Overall User Experience & 5.30 & 50 & $<.001 * * *$ & 1.484 & 3.97 & 0.81 & 2.86 & 0.68 \\
\hline $\begin{array}{l}\text { (7) Number of persons involved in } \\
\text { technology use }\end{array}$ & 3.32 & 10.17 & $.008 * *$ & 1.405 & 2.86 & 0.58 & 1.40 & 1.35 \\
\hline (23) UneeQ: Stimulation & 4.92 & 55 & $<.001 * * *$ & 1.305 & 3.01 & 0.92 & 1.77 & 0.98 \\
\hline (4) Estimated duration of waiting time & -4.60 & 44.79 & $<.001 * * *$ & 1.200 & 0.89 & 0.29 & 1.17 & 0.16 \\
\hline (9) Conversations defined as small talk & 3.92 & 49 & $<.001 * * *$ & 1.100 & 4.00 & 0.89 & 3.00 & 0.93 \\
\hline (21) UneeQ: Competence & 3.69 & 55 & $.001 * *$ & 0.972 & 2.45 & 0.64 & 1.68 & 0.92 \\
\hline (33) Number of laughs & 3.16 & 50 & $.003 * *$ & 0.898 & 13.07 & 8.62 & 6.30 & 6.27 \\
\hline (34) Intensity of laugh & 2.83 & 37.44 & $.007 * *$ & 0.859 & 1.22 & 0.21 & 1.07 & 0.13 \\
\hline $\begin{array}{l}\text { (30) Number of times participants } \\
\text { talked about the waiting time } \\
\text { (positive or negative) }\end{array}$ & 33.14 & 48.50 & $.003 * *$ & 0.858 & 2.97 & 2.77 & 0.96 & 1.82 \\
\hline (25) Number of changes of speakers & 3.05 & 51 & $.004 * *$ & 0.849 & 86.38 & 47.55 & 48.75 & 40.83 \\
\hline (17) UneeQ: Relatedness & 3.09 & 55 & $.003 * *$ & 0.823 & 2.53 & 0.95 & 1.80 & 0.82 \\
\hline $\begin{array}{l}\text { (26) Number of times participants told } \\
\text { something personal }\end{array}$ & -2.74 & 29.50 & $.010^{*}$ & 0.794 & 6.31 & 5.21 & 13.26 & 11.23 \\
\hline (18) UneeQ: Popularity & 2.11 & 55 & $.039 *$ & 0.724 & 2.08 & 0.74 & 1.62 & 0.90 \\
\hline (22) UneeQ: Influence & 2.50 & 55 & $.015^{*}$ & 0.682 & 1.89 & 0.78 & 1.43 & 0.55 \\
\hline $\begin{array}{l}\text { (15) UneeQ: Collecting meaningful } \\
\text { things }\end{array}$ & 2.56 & 39.53 & $.014 *$ & 0.671 & 1.70 & 0.88 & 1.24 & 0.40 \\
\hline $\begin{array}{l}\text { (29) Number of times participants } \\
\text { expressed suspicion about the } \\
\text { study's objective }\end{array}$ & 2.24 & 50 & $.029 *$ & 0.645 & 3.00 & 3.02 & 1.39 & 1.83 \\
\hline $\begin{array}{l}\text { (31) Type of statement about the } \\
\text { waiting time }\end{array}$ & -1.84 & 29 & .077 & 0.637 & -0.60 & 0.33 & -0.33 & 0.50 \\
\hline $\begin{array}{l}\text { (28) Number of times participants } \\
\text { talked about anything else }\end{array}$ & -2.00 & 32.87 & .054 & 0.575 & 10.48 & 9.87 & 18.65 & 17.49 \\
\hline (16) UneeQ: Self-expression & 1.54 & 55 & .128 & 0.407 & 1.72 & 0.73 & 1.45 & 0.59 \\
\hline (20) UneeQ: Physical health & 1.16 & 55 & .253 & 0.303 & 2.00 & 0.95 & 1.73 & 0.83 \\
\hline (14) UneeQ: Security & -0.95 & 47.41 & .349 & 0.247 & 1.47 & 0.58 & 1.65 & 0.85 \\
\hline (11) Agreeableness of conversations & 0.57 & 36.67 & .572 & 0.168 & 4.45 & 0.54 & 4.34 & 0.75 \\
\hline $\begin{array}{l}\text { (10) Depth of the conversation } \\
\text { correspond to the users needs }\end{array}$ & 0.53 & 49 & .599 & 0.155 & 1.55 & 0.69 & 1.45 & 0.60 \\
\hline (3) Amount of happiness & 0.49 & 55 & .623 & 0.133 & 0.71 & 0.13 & 0.68 & 0.29 \\
\hline \multirow[t]{2}{*}{ (24) Total duration of talking time } & -0.45 & 33.87 & .65 & 0.129 & 201.74 & 122.76 & 225.18 & 226.86 \\
\hline & -0.40 & 48 & .694 & 0.111 & 1.00 & 1.73 & 1.17 & 1.30 \\
\hline
\end{tabular}


Table 5 (continued)

\begin{tabular}{|c|c|c|c|c|c|c|c|c|}
\hline \multirow[t]{2}{*}{ Variable } & \multirow[t]{2}{*}{$\mathrm{T}$} & \multirow[t]{2}{*}{ df } & \multirow[t]{2}{*}{ Sig. } & \multirow[t]{2}{*}{$\mathrm{d}$} & \multicolumn{2}{|c|}{ Snackomat } & \multicolumn{2}{|c|}{ Coffee machine } \\
\hline & & & & & M & SD & M & $\mathrm{SD}$ \\
\hline \multicolumn{9}{|l|}{$\begin{array}{l}\text { (32) Duration of time participants used } \\
\text { other items }\end{array}$} \\
\hline (5) Positive utilization of waiting time & 0.39 & 56 & .697 & 0.108 & 3.75 & 0.62 & 3.68 & 0.68 \\
\hline (1) Positive affect & 0.33 & 56 & .743 & 0.088 & 29.38 & 7.00 & 28.79 & 6.51 \\
\hline (2) Negative affect & -0.25 & 56 & .807 & 0.064 & 12.21 & 2.53 & 12.38 & 2.81 \\
\hline \multirow[t]{2}{*}{ (19) UneeQ: Competition } & -.12 & 55 & .905 & 0.022 & 1.23 & 0.65 & 1.25 & 0.62 \\
\hline & & & & & \multicolumn{2}{|c|}{ Snackomat } & \multicolumn{2}{|c|}{ Coffee machine } \\
\hline Variable & $x^{2}$ & df & Sig. & & Yes & No & Yes & No \\
\hline (6) Use of the respective technology & 27.25 & 1 & $<.001 * * *$ & & 29 & 0 & 10 & 18 \\
\hline
\end{tabular}

Notes. $* * * p<.001$ (Bonferroni corrected), $* * p<.01, * p<.05$

expressed suspicions about the study's objective, in the (30) number of times they talked about the waiting time (positive and negative), in (31) the type of statements they made about the waiting time (positive or negative), in the (32) duration of time they used other items (e.g. smartphone, magazine), in the (33) number of laughs and in the (34) intensity of laugh.

In summary when Bonferroni correction was applied there were the following significant differences between the two conditions:

- People in the Snackomat condition perceived the duration of the waiting time as shorter.

- People in the Snackomat condition used the provided technology more often.

- The Snackomat had a greater positive influence on the conversations.

- In the Snackomat condition conversations were defined as small talk more often.

- In the Snackomat condition the technology had a greater positive influence on the waiting time.

- The overall User Experience of the Snackomat was rated better.

- The Snackomat was perceived as more stimulating.

- Participants in the Snackomat condition talked more about the technology in the room.

We conducted 34 single comparisons and applied the Bonferroni correction to prevent an alpha error inflation. Bonferroni correction is not used without criticism (García 2004; Nakagawa 2004). The reduction of the alpha level reduces the statistical power and therewith increases the chances for a Type II error (Nakagawa 2004). Nakagawa (2004) recommends instead of reducing the alpha level to report the effect sizes of the comparisons. Therefore we calculated Cohen's d for each single comparison (see Table 5). Effect sizes between $d=0.2-d=0.5$ are defined as small effect sizes, $d=$ $0.5-\mathrm{d}=0.8$ represent medium effect sizes and $\mathrm{d}>0.8$ represent large effect sizes. If we had not applied the Bonferroni correction even more comparisons would have been 
significant. In the following section we will list the results, which also would have been significant without Bonferroni correction. They all have medium sized or large effect sizes $(\mathrm{d}>0.8)$.

- In the Snackomat condition (7) more persons were involved in the technology use $(\mathrm{d}=1.41)$.

- The Snackomat addressed more the needs for (21) competence ( $d=0.97)$, for (17) relatedness $(d=0.82)$, for (18) popularity $(d=0.72)$, for (22) influence $(d=0.62)$ and for (15) collecting meaningful things $(d=0.67)$.

- In the Snackomat condition participants laughed more often (Snackomat: $d=0.90$ ) and with more intensity $(d=0.86)$.

- In the Snackomat condition participants more often talked about the waiting time $(d=0.86){ }^{3}$

- In the Snackomat condition there were more changes of speakers $(d=0.85)^{4}$

- In the Snackomat condition participants told less often something personal $(d=$ $0.79)$.

- In the Snackomat condition participants more often expressed suspicion about the study's objective $(d=0.65)$.

\section{Discussion}

In the present study we used the Snackomat, a vending machine offering snacks for free. Its objective is not just to offer snacks, but primarily to initiate small talk between people in waiting situations, thus, create a positive experience. The effect of the Snackomat on a waiting situation was compared with the effect of a coffee machine as a control condition. Therefore, we brought two to four people into a waiting situation of $25 \mathrm{~min}$. Participants were blind to the study's objective. The waiting situation was recorded on video. After the waiting situation participants were asked to fill in several questionnaires. We assumed that participants in the Snackomat condition would feel more positive after the waiting situation than people in the coffee machine condition and that they would evaluate the waiting time better. In the discussion we take into consideration all effects that became significant because the effects that were significant without Bonferroni correction consistently had large or medium sized effect sizes. It can thus be assumed that they would have become significant with a larger sample.

Our two hypotheses could be confirmed to a large extent but not completely. We assumed that (hypothesis 1) people would feel better after a waiting situation with the Snackomat than after a waiting situation with the coffee machine. The results show that the overall user experience is more positive for the Snackomat than for the coffee machine condition. Furthermore, the Snackomat addressed more the psychological need for stimulation which shows that the Snackomat serves curiosity animating to communicate and to interact with the Snackomat and other persons in the waiting situation. However, we were not able to detect differences in positive or negative affect or in the momentary feeling of happiness after the waiting situation.

\footnotetext{
${ }^{3}$ Including neuroticism as a covariate did not change the results, $\mathrm{F}(1,49)=9.85, p=.003$.

${ }^{4}$ Including openness to experience as a covariate did not change the results, $\mathrm{F}(1,50)=8.46, p=.005$.
} 
Furthermore, we assumed that (hypothesis 2) people would rate the quality of the waiting situation with the Snackomat better than the waiting situation with the coffee machine. This hypothesis is supported by the fact that people in the Snackomat condition perceived the duration of the waiting time as shorter and that the Snackomat had a greater positive influence on the conversations and the waiting time. This result might be due to the fact that people used the Snackomat more often than the coffee machine, and that they also talked more about this technology.

We can thus say that we were quite successful in creating good conversations and positive experiences. Due to the duration of the process the Snackomat seems especially appropriate for longer waiting situations where people stay in the same waiting area and not for short waiting situations. As it has the intention to bring unknown people into contact it could be permanently installed in waiting situations where people are rarely but for a certain amount of time like at the doctor's waiting room or at the airport.

Further results are discussed in the following:

\subsection{Differences in the Mood after the Waiting Situation}

There were no differences in affect and in the momentary feeling of happiness after the waiting situation, which means that there was no difference in the general mood (see Table 5). These results are astonishing as in the Snackomat condition the overall user experience was more positive compared to the coffee machine condition. Maybe participants were positively excited because just before filling out the questionnaires they had been told that the group discussion was not the focus of the study. Instead, they were told, to first complete the questionnaires before being debriefed fully about the actual study question. A recency effect may have been occurred in a way that especially this induced excitement affected the mood evaluation (Bruun and Ahm 2015).

\subsection{Evaluation of the Waiting Situation}

Some results contradict our hypothesis while some support it. Participants did not differ in their evaluation of the positive utilization of the waiting time and the agreeableness of the conversations. Both variables were rated quite high in both conditions (Positive utilization of the waiting time [Snackomat: $M=3.75, S D=0.62$, control: $M=3.68, S D=0.68$ ] and agreeableness of conversations [Snackomat: $M=4.45, S D=0.54$, control: $M=4.34, S D=$ $0.75]$ ), indicating that both situations were quite agreeable. This may be due to the fact that participants had been told at the beginning of the waiting situation that, even though they had to wait, the whole study would not take much longer than the advertised 60 min. Thus, people did not feel uncomfortable because they had planned with this duration in mind and did not perceive the waiting as wasted time.

In the Snackomat condition the topics of conversation were defined as small talk more often than in the control condition (see Table 5, variable 9). This result by itself is neither positive nor negative especially when considering that the groups did not differ in their need for more depth in their conversations.

In contrast, other aspects of the results seem to favor the Snackomat. First, the perceived waiting time seemed shorter in the Snackomat condition (see Table 5, variable 4). Furthermore, the positive evaluation of the conversation and the waiting time as a whole was affected more by the Snackomat than by the coffee machine. 


\subsection{What Happened during Waiting?}

The Snackomat was used more often than the coffee machine and additionally more people were involved in the usage of the technology. Participants did not talk more in either of the two conditions concerning the total duration of speaking but with the Snackomat people talked more about the technology.

There was no difference in how often they occupied themselves with other devices such as magazines or smartphones. Keeping in mind the conditions under which the study was conducted, these results can be explained with the composition of the sample. Almost all participants studied at the same university, thus having the same background and a breadth of shared topics they could talk about. In a natural waiting situation most people do not share such a common ground. Therefore, it can be assumed that outside of the lab setting people in the control condition would not have talked that much to each other, especially not so personally. This could also be an explanation for the fact that we were not able to find differences in mood between the two groups. The positive affect in the Snackomat condition could be explained by participants laughing a lot, whereas in the control condition they talked more about personal topics. In the experimental condition the Snackomat might have distracted people more and, thus inhibited a conversation on a more personal level. But, this level of personal conversation would most likely not have occurred in a natural setting.

\subsection{What Needs Are Fulfilled through the Respective Technology?}

Overall, participants rated the user experience of the Snackomat better than that of the coffee machine. The Snackomat fulfilled the psychological need for stimulation significantly more with a large effect size (see Table 5 , variable 23). It can be assumed that the Snackomat was more animating and that it added fun and diversion into the waiting situation. In addition, this indicates that it positively influenced the conversations and the whole waiting time. They perceived the waiting time as shorter, something that happens when the time period is filled with activities and distractions. This result can be explained by the fact that the Snackomat was used more frequently than the coffee machine and also more frequently as a group. It seems that this technology animated people to interact with each other more. Our results also support the statement of Coupland (2003) that small talk reduces the fear of social contact. As we have seen, participants felt that they engaged in more small talk in the Snackomat condition compared to the control group. Further, people interacted more when getting snacks than when having coffee, and they were also more talkative (see Table 5 , variable 7,8 , $9,12,27)$. It seems that this technology brings fun to people in that it instructs them to do something together. The other psychological needs measured showed mostly low ratings as well as no or marginal differences between the conditions (competence, relatedness, security, physical health, self-expression, collecting meaningful things, competition, influence, and popularity).

The situation with the coffee machine did not engage people in the same way which is probably why people talked more about personal things and topics unrelated to the technology. It seems astonishing that people talked that much even without the Snackomat as in normal waiting situations people do not interact as much. But one thing to keep in mind is that they formed a group the moment they met in front of the 
office and they all knew then that they would have the same task for the next hour. Furthermore, most of them were students from different programs at the same university. This means, while they did not know each other personally, they had a common background which reduces uncertainty according to the AUM theory (Duronto et al. 2005). Our results do not support the findings of Mehl et al. (2010) who found a positive correlation between well-being and substantive conversation. We did not find differences between the groups in affect and momentary feeling of happiness although they differed in the amount of small talk. Even when we correlated the evaluation of the conversation as small talk with the affect scales (PANAS positive and negative affect, momentary feeling of happiness), no relationship reached significance. Thus, we cannot say that substantive conversation is better than small talk and we can assume that small talk is better than no talk. But what can definitely be confirmed is the assumption that technology can be used to initiate small talk.

When we consider the five characteristics of Positive Design formulated by Desmet and Pohlmeyer (2013) and compare the concept of the Snackomat and the results of the experiment with them we come to the conclusion that we mostly considered them.

The concept of the Snackomat was not intended to solve a given problem but to create positive experiences in situations which to date are not usually considered as happy situations. We followed the principle of Possibility driven Design (Desmet and Hassenzahl 2012) and managed to make people laugh and to bring them in a diversified conversation. Positive Design requires a balance between its three pillars (Design for Pleasure, Design for personal significance, Design for virtue). Focusing one aspect of Positive Design may not be addressed at the expense of another aspect. Participants showed having fun in the Snackomat condition. We do not see any chance how the concept may be dangerous to the other two pillars if an eye is kept on the need for selfdetermination. Interviews revealed that people must be given the choice between using the technology and interacting with other people and choosing not to. Personal fit implies providing targeted solutions for some users in contrast to raising the claim to involve all users. We think that concerning the Snackomat this criterion is similar to that of balance: Although the technology presented here is designed to animate people to use it, in the end only those interested in talking to strangers represent the target group. Throughout the design process users were actively involved. The idea of the "Snackomat "was derived from interview results on positive experiences during air travel (Burmester and Tille 2013). In the beginning users were involved in the designprocess as interview partners (Laib et al. 2014). With the possibility of a controlled experiment we could observe direct reactions of the users to the technological device and ask them about their experiences and attitudes afterwards. We did not directly measure the long-term impact of the Snackomat. As the goal of it is to initiate small talk, to bring people together and therewith to evoke positive emotions we hope to contribute to the overall subjective well-being and to improve the situation of waiting.

This study shows, waiting situations can be created in a way that they are experienced positively. Future studies on technology for waiting situations can build on the theoretical background of this study as the need oriented user experience model (Hassenzahl 2008; Hassenzahl et al. 2010; Diefenbach and Hassenzahl 2017), positive design (Desmet and Pohlmeyer 2013), AUM theory (Gudykunst and Ting-Toomey 1988; Gudykunst 1998; Duronto et al. 2005), as well as small talk models (Beinstein 1975; Coupland 2003; Mehl et al. 2010). For the design of Snackomat the following principles were developed and can 
be used for future studies: catching the attention of persons in a waiting situation, bring them together in front of a technology, offer small gifts just for a group of persons (the gifts should be different and preferably unknown to the persons), provide possibilities to have small talk with others by providing save topics, offer possibilities to interact with the other persons, and all persons in a waiting situation should always be free to participate in conversation and interaction with others and the technology or not. These design principles can be tested and extended by future studies in real waiting situations.

When planning studies, it seems to be promising to analyze the conversation and interaction behavior, like number and intensity of laughter as an indicator of fun and frequency of turn-taking as measures of conversational activity, as well as documentation of conversation topics (e.g. personal themes, waiting situation, technology) (see Table 5, variable 25, 26, 30, 31).

\subsection{Limitations}

Nearly all participants were students of the same university what makes them members of the same community and gives them a common platform. All results have to be interpreted in the context of a likely reduction of the inhibition threshold.

The waiting situation was an experimental setting and people were deceived in order to observe their natural behaviour. As we have seen the deception did not function equally well in both situations. We see that participants in the coffee machine condition expressed less suspicion than in the experimental condition. But the video analyses revealed that the conversations in the Snackomat condition were not influenced by the assumed observation.

Participants in the Snackomat condition received coins whether participants in the control condition did not. Thus, the fact that the Snackomat was used more often than the coffee machine might be traced back to the circumstance that people might have had the feeling they have to use their coin. Actually, the snacks were for free and also in a realistic scenario the use of the Snackomat should be free of charge. Therefore, in future studies the design rationale of the Snackomat should be revised with respect to a use without coins.

Of course, participant personality plays an important role in a conversation process. One can easily imagine how different a situation turns out when four very shy people wait together in comparison to four outgoing and self-confident ones. This is why we controlled for neuroticism, extraversion and openness to experience. But there may be other personality variables that might have confounded the results, for example, curiosity (Kashdan et al. 2011). Furthermore, the personal level of tolerance of ambiguity (Mclain 1993; Furnham and Marks 2013) should be measured and controlled.

Conducting this type of study takes an enormous amount of time and effort. Even if we are grateful to have had the opportunity to research the behavior of 58 participants we are well aware that the study is underpowered. The reported results have to be interpreted in the context of this restricted study design. Future studies are required to verify the inferences we have made based on our results.

\section{Future Studies}

To our knowledge this was the first study measuring the effect of a new technology on positive experience by positive communication with strangers of waiting times 
situation in an experimental setting. The results answer several relevant questions, other questions remain unanswered and should be addressed in future studies. The interviews of a first study (Laib et al. 2014) revealed that people believe that mutual sympathy is a crucial factor when deciding whether to address another person or using the Snackomat with them. It would thus be interesting to investigate how a factor like sympathy or relatedness or feelings of closeness (Kashdan et al. 2011) moderates the effect of the Snackomat.

With the Snackomat we animated people to interact and to have fun together. We did not manage to make people talk about personal topics. It would be interesting to investigate how the Snackomat had to be designed to animate people to talk more about topics, which are less superficial than small talk and more personal. When designing the Snackomat we chose a safe content like snacks, assuming that nobody would have a problem talking about food. What would have had happened, however, if we had designed the machine to trigger personal conversations, for example by stimulating more personal subjects of conversation. Would they have used the automat with the same frequency as the Snackomat or would it have been perceived as an infringement to privacy? Future studies should address this question.

After proving its right to exist in the experimental setup the Snackomat has to be implemented next in a natural setting where it has to be investigated how it functions when people have nothing in common besides waiting together (e.g. waiting in the doctors office).

As mentioned above the Snackomat study has the character of a pilot study. We are well aware that every pilot study offers possibilities for improvements in the study design. We also recognized that not all findings supported our hypotheses. Nevertheless, to our opinion the findings have to be emphasized at the end: First, the study findings point towards the expected the direction, it seems as if the Snackomat improves the waiting experience and is thus worth to be elaborated and improved. Second, the intention of the Snackomat is contributing to the idea of a good life in being designed to create positive waiting experiences. Even if there are improvements needed the rationale behind this kind of technology is valuable and extraordinary and the path of designing this kind of technology that simply contribute to positive experiences has to be continued. Third, the interdisciplinary approach of design, computer science and psychology seems to be a promising way.

Funding Information Open Access funding provided by Projekt DEAL. This study was partially funded by intern research and innovation funding (Hochschul-Invest) that Ralph Tille received from Stuttgart Media University (his employer).

\section{Compliance with Ethical Standards}

Conflict of Interest The authors declare that they have no conflict of interest.

Open Access This article is licensed under a Creative Commons Attribution 4.0 International License, which permits use, sharing, adaptation, distribution and reproduction in any medium or format, as long as you give appropriate credit to the original author(s) and the source, provide a link to the Creative Commons licence, and indicate if changes were made. The images or other third party material in this article are included in the article's Creative Commons licence, unless indicated otherwise in a credit line to the material. If material is not included in the article's Creative Commons licence and your intended use is not permitted by statutory regulation or exceeds the permitted use, you will need to obtain permission directly from the copyright holder. To view a copy of this licence, visit http://creativecommons.org/licenses/by/4.0/. 


\section{References}

Abdel-Khalek, A. M. (2006). Measuring happiness with a single-item scale. Social Behavior and Personality, 34(2), 139-150. https://doi.org/10.2224/sbp.2006.34.2.139.

Asthana, S., Singh, P. and Gupta, P. (2015) 'Survival Analysis', in Proceedings of the 33rd Annual ACM Conference on Human Factors in Computing Systems - CHI '15, pp. 367-376. doi: https://doi. org/10.1145/2702123.2702428.

Beinstein, J. (1975) 'Small talk as social gesture.', Journal of Communication, 25(4).

Borkenau, P. and Ostendorf, F. (2008) NEO-FFI: NEO-Fünf-Faktoren-Inventar nach Costa und McCrae, Manual. 2nd edn. Göttingen: Hogrefe. Available at: http://pub.uni-bielefeld.de/publication/1900471 (Accessed: 20 August 2014).

Botella, C., \& Riva, G. (2012). The present and future of positive technologies. CyberPsychology, Behavior, and Social Networking, 15(2), 78-84.

Bournes, D. A., \& Mitchell, G. J. (2002). Waiting: the experience of persons in a critical care waiting room. Research in nursing \& health, 25(1), 58-67.

Bradley, M., \& Lang, P. J. (1994). Measuring Emotion: The Self-Assessment Semantic Differential Manikin and the. Journal of Behavior Therapy and Experimental Psychiatry, 25(I), 49-59. https://doi.org/10.1016 /0005-7916(94)90063-9.

Bruun, A., \& Ahm, S. (2015). Mind the Gap! Comparing Retrospective and Concurrent Ratings of Emotion in User Experience Evaluation. In J. Abascal et al. (Eds.), Human-Computer Interaction - INTERACT 2015 (pp. 89-109). Cham: Springer. https://doi.org/10.1007/978-3-319-22,701-6.

Burmester, M., \& Tille, R. (2013). Travel Experience - Erlebniszentrierte Gestaltung neuer Medien für Reisende. In H. Brau et al. (Eds.), Usability Professionals 2013 (pp. 146-151). Stuttgart: German UPA e.V.

Costa, P. J., \& McCrae, R. (1992). Neo personality inventory-revised (neo-pi-r) and neo five-factor inventory (neo-ffi) professional manual, Odessa, FL: Psychological Assessment Resources. Odessa: Psychological Assessment Resources.

Coupland, J. (2003). 'Small Talk: Social Functions', Research on Language \& Social Interaction. Routledge, 36(1), 1-6.

Desmet, P. M. A., \& Hassenzahl, M. (2012). Towards happiness : Possibility-driven design. In M. Zacarias \& J. V. de Oliveira (Eds.), Human-computer interaction: The agency perspective (pp. 1-27). New York: Springer.

Desmet, P. M. A., \& Pohlmeyer, A. E. (2013). 'Positive Design: An Introduction to Design for Subjective Well-Being', International Journal of Design; Vol 7, No 3 (2013), 7(3), pp. 5-19. Available at: http:/www.ijdesign.org/ojs/index.php/IJDesign/article/view/1666/595.

Diefenbach, S., \& Hassenzahl, M. (2017). Psychologie in der nutzerzentrierten Produktgestaltung. Berlin: Springer.

Duronto, P. M., Nishida, T., \& Nakayama, S. I. (2005). Uncertainty, anxiety, and avoidance in communication with strangers. International Journal of Intercultural Relations, 29(5), 549-560. https://doi.org/10.1016/j. ijintrel.2005.08.003.

Durrande-Moreau, A., \& Usunier, J.-C. (1999). Time Styles and the Waiting Experience: An Exploratory Study. Journal of Service Research, 2(2), 173-186.

Field, A. (2013). Discovering statistics using IBM SPSS statistics (4th ed.). London: SAGE Publications.

Frank, A., et al. (2015). Advanced Traffic Light Interface: Countdown Timers to Increase User Experience. In AutomotiveUI '15 Adjunct, September 01-03, 2015 (pp. 56-61). United Kingdom: Nottingham. https://doi.org/10.1145/2809730.2809737.

Fraunhofer-IAO (2014) UneeQ - User Needs Questionnaire.

Fredrickson, B. L. (2001). 'The role of positive emotions in positive psychology: The broaden-and-build theory of positive emotions.', American psychologist. American Psychological Association, 56(3), 218226.

Fronemann, N. and Peissner, M. (2014) 'User Experience Concept Exploration - User Needs as a Source for Innovation', in NordiCHI '14: The 8th Nordic Conference on Human-Computer Interaction Proceedings.

Furnham, A., \& Marks, J. (2013). Tolerance of Ambiguity: A Review of the Recent Literature. Psychology, 04(09), 717-728. https://doi.org/10.4236/psych.2013.49102.

García, L. V. (2004). Escaping the Bonferroni iron claw in ecological studies. Oikos, 105(3), 657-663.

Gudykunst, W. B. (1998). Applying anxiety/uncertainty management (AUM) theory to intercultural adjustment training. International Journal of Intercultural Relations, 22, 227-250. 
Gudykunst, W. B., \& Ting-Toomey, S. (1988). Culture and interpersonal communication. Newbury Park: Sage.

Hassenzahl, M. (2008) 'User experience (UX): towards an experiential perspective on product quality', in Proceedings of the 20th International Conference of the Association Francophone d'Interaction HommeMachine. ACM, pp. 11-15. Available at: http://portal.acm.org/citation.cfm?id=1512717.

Hassenzahl, M. (2010). Experience Design: Technology for All the Right Reasons. Breiningsville: Morgan \& Claypool 2200/S00261ED1V01Y201003HCI008.

Hassenzahl, M., et al. (2013). Designing Moments of Meaning and Pleasure. Experience Design and Happiness Understanding Experiences. International Journal of Design, 7(3), 21-31.

Hassenzahl, M., Diefenbach, S., \& Göritz, A. (2010). Needs, affect, and interactive products - Facets of user experience. Interacting with Computers, 22(5), 353-362. https://doi.org/10.1016/j.intcom.2010.04.002.

Ho, C. S., Yeh, M. L., \& Liao, Y. S. (2014). Study of patient waiting time in the emergence department: An example of a medical center in new Taipei county, Taiwan. Applied Mechanics and Materials, 519-520, 1579-1582. https://doi.org/10.4028/www.scientific.net/AMM.519-520.1581.

Kanis, M., \& Brinkman, W. P. (2007). What do people like? In Proceedings of the 14th European conference on Cognitive ergonomics invent! explore! - ECCE '07 (pp. 191-198). New York: ACM Press.

Kashdan, T. B., et al. (2011). When curiosity breeds intimacy: taking advantage of intimacy opportunities and transforming boring conversations. Journal of personality, 79(6), 1369-1402.

Kok, B. E., et al. (2013). 'How Positive Emotions Build Physical Health Perceived Positive Social Connections Account for the Upward Spiral Between Positive Emotions and Vagal Tone', Psychological science. Sage Publications, 24(7), 1123-1132.

Körner, A., Geyer, M., \& Brähler, E. (2002). Das NEO-Fünf-Faktoren Inventar (NEO-FFI) - Validierung anhand einer deutschen Bevölkerungsstichprobe. Diagnostica, 48(1), 19-27.

Krohne, H. W. et al. (1996) 'Untersuchungen mit einer deutschen Version der' Positive and Negative Affect Schedule"(PANAS).', Diagnostica.

Kutash, M., \& Northrop, L. (2007). Family members' experiences of the intensive care unit waiting room. Journal of advanced nursing, 60(4), 384-388.

Laib, M., Burmester, M., Kulzer, M., Pfaff, F., \& Reibke, A. P. (2014). Snack-O-Mat a machine for initiating small talk in waiting situations. In A. Bischof et al. (Eds.), CrossWorlds: Theory, Development \& Evaluation of Social Technology (pp. 1-7). Chemnitz: Technische Universität Chemnitz.

Lambert, N. M., et al. (2012). A boost of positive affect: The perks of sharing positive experiences. Journal of Social and Personal Relationships, 30(1), 24-43.

Lyubomirsky, S. (2007). The how of happiness: A scientific approach to getting the life you want. London: Penguin.

Mclain, D. L. (1993). he MSTAT-I: A new measure of an individual's tolerance for ambiguity. Educational and Psychological Measurement, 53, 183-189. https://doi.org/10.1177/0013164493053001020.

Mehl, M. R., et al. (2010). Eavesdropping on happiness: well-being is related to having less small talk and more substantive conversations. Psychological science, 21(4), 539-541.

Miller, G. A., \& Chapman, J. P. (2001). Misunderstanding analysis of covariance. Journal of abnormal psychology, 110(1), 40-48.

Minton, H. (2008) 'Waiting and queuing in the check-in hall: An ethnographic study of queuing and waiting for check-in services at Manchester Airport', in Journal of Airport Management.

Nakagawa, S. (2004). A farewell to Bonferroni: the problems of low statistical power and publication bias. Behavioral Ecology, 15(6), 1044-1045.

Nie, W. (2000). Waiting: integrating social and psychological perspectives in operations management. Omega, 28(6), 611-629.

Noldus (2010) 'Observer XT'.

Norman, D. (2008) The psychology of waiting lines, Excerpt of.

Reiss, S. and Havercamp, S. M. (1998) 'Toward a Comprehensive Assessment of Fundamental Motivation: Factor Structure of the Reiss Profiles', Psychological Assessment. [Arlington, VA]: American Psychological Association,[c1989-, 10(2), pp. 97-106. Available at: http://psycnet.apa.org/index. $\mathrm{cfm} ? \mathrm{fa}=$ fulltext.journal\&amp;jcode=pas\&amp; $\mathrm{vol}=10 \& \mathrm{amp} ;$ issue=2\&amp;format=html\&amp;page=97 \&amp; expand $=1$.

Russell, J. A., Weiss, A., \& Mendelsohn, G. A. (1989). Affect Grid: A Single-Item Scale of Pleasure and Arousal. Journal of Personality and Social Psychology, 57(3), 493-502. https://doi.org/10.1037/00223514.57.3.493.

Ryan, R. M., \& Deci, E. L. (2000). Self-determination theory and the facilitation of intrinsic motivation, social development, and well-being. The American psychologist, 55(1), 68-78 http://www.ncbi.nlm.nih. gov/pubmed/11392867. 
Seligman, M. (2012). Flourish - Wie Menschen aufblühen: Die Positive Psychologie des gelingenden Lebens. München: Kösel-Verlag.

Seligman, M. E. P., \& Csikszentmihalyi, M. (2000). Positive psychology: An introduction. American Psychologist, 55(1), 5-14. https://doi.org/10.1037//0003-066X.55.1.5.

Sheldon, K. M., et al. (2001). 'What is satisfying about satisfying events? Testing 10 candidate psychological needs', Journal of personality and social psychology. Apa American Psychological Association, 80(2), 325-339. https://doi.org/10.1037//O022-3514.80.2.325.

Sykes, R. E. (1983). Initial Interaction Between Strangers And Acquaintances A Multivariate Analysis of Factors Affecting Choice of Communication Partners. Human Communication Research, 10(1), 27-53. https://doi.org/10.1111/j.1468-2958.1983.tb00003.x.

Watson, D., Clark, L., \& Tellegen, A. (1988). Development and validation of brief measures of positive and negative affect: the PANAS scales. Journal of personality and social psychology, 54(6), 1063.

Zhou, R., \& Soman, D. (2008). 'Consumers' Waiting in Queues: The Role of First-Order and Second-Order Justice. Psychology \& Marketing, 25(3), 262-279.

Publisher's Note Springer Nature remains neutral with regard to jurisdictional claims in published maps and institutional affiliations. 